Article

\title{
Carbon Self-Doped Carbon Nitride Nanosheets with Enhanced Visible-Light Photocatalytic Hydrogen Production
}

\author{
Hongwei Wang ${ }^{1}$, Guiqing Huang ${ }^{1}$, Zhiwei Chen ${ }^{2}$ and Weibing $\mathrm{Li}^{2, *}$ \\ 1 School of Environmental Science and Engineering, Qingdao University, Qingdao 266071, China; \\ hwwang6688@126.com (H.W.); hgq_112513@163.com (G.H.) \\ 2 School of Environment and Safety Engineering, Qingdao University of Science and Technology, \\ 53 Zhengzhou Road, Qingdao 266042, China; chenzhiwei1204@163.com \\ * Correspondence: lwbing@qust.edu.cn; Tel.: +86-532-8402-2617
}

Received: 29 July 2018; Accepted: 27 August 2018; Published: 29 August 2018

\begin{abstract}
In this study, we prepared carbon self-doped carbon nitride nanosheets through a glucose synergic co-condensation method. In the carbon self-doped structure, the $\mathrm{N}$ atoms in the triazine rings were substituted by $\mathrm{C}$ atoms, resulting in enhanced visible-light photocatalytic hydrogen production, which is three-times higher than that of bulk carbon nitride. The enhanced photocatalytic hydrogen production was attributed to the higher charge-carrier transfer rate and widened light absorption range of the carbon nitride nanosheets after carbon self-doping. Thus, this work highlights the importance of carbon self-doping for improving the photocatalytic performance. Meanwhile, it provides a feasible method for the preparation of carbon self-doped carbon nitride without destroying the $2 \mathrm{D}$ conjugated backbone structures.
\end{abstract}

Keywords: carbon nitride nanosheets; carbon self-doping; photocatalytic hydrogen production; charge transfer rate

\section{Introduction}

Environmental pollution and energy crises have been seriously threatening the survival of mankind and the sustainable development of society. The photocatalysis technique is considered as an environmentally friendly technology to solve these problems because of its characteristics of being green, its low energy consumption and sustainable recycling [1].

In 2009, Wang et al. [2] reported graphene-like carbon nitride $\left(\mathrm{g}-\mathrm{C}_{3} \mathrm{~N}_{4}\right)$ as a novel metal-free polymer semiconductor photocatalyst in water splitting for the first time. $\mathrm{g}-\mathrm{C}_{3} \mathrm{~N}_{4}$ has attracted a lot of attention because of its suitable bandgap, abundant composition elements and visible-light response. However, g- $\mathrm{C}_{3} \mathrm{~N}_{4}$ is limited in practical applications due to its small specific surface area and serious photocarrier recombination. Therefore, it is urgent to increase the specific surface area and the photocarrier transport rate of $\mathrm{g}-\mathrm{C}_{3} \mathrm{~N}_{4}$.

Traditional g- $\mathrm{C}_{3} \mathrm{~N}_{4}$ generally shows a layered structure that is formed by stacking a large number of two-dimensional triazine ring nanosheets [3]. Modification of the micromorphology can effectively increase the specific surface area and improve the photocatalytic performance. Ultrathin $g-C_{3} \mathrm{~N}_{4}$ flake (UF-CN) was prepared through a facile wet mechanical grind method [4]. With a yield rate of $90 \%$, the prepared UF-CN showed higher photocatalytic hydrogen production and photocatalytic degradation rate. Han et al. [5] treated "seaweed" architecture $\mathrm{g}-\mathrm{C}_{3} \mathrm{~N}_{4}$ by direct calcination of the freeze-dried precursor. The as-prepared samples showed increased active sites, improved electron transfer ability and increased visible-light response, which resulted in the enhancement of the photocatalytic performance. 
Design and construction of g- $\mathrm{C}_{3} \mathrm{~N}_{4}$-based heterojunctions can effectively accelerate the transport and transfer of photocarriers, greatly reducing the recombination rate of photocarriers and improving the photocatalytic performance. Various materials, such as $\mathrm{CdS}$ [6,7], $\mathrm{MoS}_{2}$ [8], $\mathrm{ZnO}$ [9] and $\mathrm{TiO}_{2}$ [10], have been used for constructing g- $\mathrm{C}_{3} \mathrm{~N}_{4}$-based heterojunctions. However, the heterostructure would reduce the redox ability of the photocarriers, which weakened the energy driving the photocatalytic process. Another commonly used modification method is doping, which can modulate the electronic structure of $\mathrm{g}-\mathrm{C}_{3} \mathrm{~N}_{4}$ to improve the photocatalytic performance. Lan et al. [11] proposed a Br-modified g- $\mathrm{C}_{3} \mathrm{~N}_{4}$ through thermal polycondensation of the mixture of urea and $\mathrm{NH}_{4} \mathrm{Br}$. The introduction of bromine modulated the electronic structure, optical absorption, conductivity and charge-carrier transfer rate of g- $\mathrm{C}_{3} \mathrm{~N}_{4}$ without changing the polymer architecture of the g- $\mathrm{C}_{3} \mathrm{~N}_{4}$, leading to enhanced photocatalytic performance. Zhang et al. [12] prepared I-modified g- $\mathrm{C}_{3} \mathrm{~N}_{4}$ by a simple in-situ surface modification method. The modification enhanced the visible-light absorption, accelerated the transfer rate of photocarriers, and finally increased the photocatalytic hydrogen production rate. Many other dopant atoms, such as S [13], P [14], B [15] and F [16], have been adopted to dope in the triazine structure of $\mathrm{g}-\mathrm{C}_{3} \mathrm{~N}_{4}$. However, the introduction of heterogeneous atoms is likely to cause asymmetric doping or impurities, which can serve as recombination centers for the photogenerated electrons and holes, therefore reducing the photocatalytic performance. Carbon materials such as graphene, graphdiyne, carbon nanotube and carbon quantum dots have been considered as potential materials to couple with photocatalysts to construct effective composite photocatalysts due to their unique physical properties and optical properties [17]. Moreover, the introduction of carbon into g- $\mathrm{C}_{3} \mathrm{~N}_{4}$ could effectively avoid the generation of impurities. Therefore, morphology control and element doping may effectively improve the photocatalytic performance of g- $\mathrm{C}_{3} \mathrm{~N}_{4}$.

Inspired by these works, we prepared a carbon self-doped $g-\mathrm{C}_{3} \mathrm{~N}_{4}$ nanosheet $\left(C-\mathrm{C}_{3} \mathrm{~N}_{4} \mathrm{NS}\right)$ by heating the mixture of bulk g- $\mathrm{C}_{3} \mathrm{~N}_{4}$ and glucose, expecting to improve the photocatalytic performance of $\mathrm{g}-\mathrm{C}_{3} \mathrm{~N}_{4}$. The bulk g- $\mathrm{C}_{3} \mathrm{~N}_{4}$ was obtained by the traditional thermal polymerization, while the secondary heat treatment can effectively exfoliate the layered g- $C_{3} N_{4}$ into the $C_{3} N_{4}$ nanosheet $\left(C_{3} N_{4}\right.$ NS) and introduce the $C$ element into the triazine structure. Therefore, the obtained $C-C_{3} N_{4}$ NS showed enhanced visible-light photocatalytic hydrogen production.

\section{Results and Discussion}

Figure $1 \mathrm{~A}, \mathrm{~B}$ presents typical SEM images of $\mathrm{C}_{3} \mathrm{~N}_{4} \mathrm{NS}$ and $0.4 \mathrm{C}-\mathrm{C}_{3} \mathrm{~N}_{4} \mathrm{NS}$. The $\mathrm{C}_{3} \mathrm{~N}_{4}$ NS (Figure $1 \mathrm{~A}$ ) exhibits a simple typical layered structure, which is similar to that of bulk $\mathrm{C}_{3} \mathrm{~N}_{4}$. The layered structure of the $\mathrm{C}_{3} \mathrm{~N}_{4} \mathrm{NS}$ was exfoliated by a thermal oxidation etching process [18].

However, the layered structures of $0.4 \mathrm{C}-\mathrm{C}_{3} \mathrm{~N}_{4}$ NS (Figure 1B) are corroded, which might be ascribed to the introduction of $C$ atoms. To investigate the state of $C$, high-resolution transmission electron microscope (HRTEM) was tested. As shown in Figure $1 C, D, C_{3} N_{4} N S$ and $0.4 C-C_{3} N_{4} N S$ samples exhibit ultrathin nanoflakes with layered structure, and no obvious carbon particles adhered to the $\mathrm{C}_{3} \mathrm{~N}_{4} \mathrm{NS}$ surface are observed in the $0.4 \mathrm{C}-\mathrm{C}_{3} \mathrm{~N}_{4} \mathrm{NS}$, indicating that the $\mathrm{C}$ might be embedded in the structure of the tri-s-triazine ring.
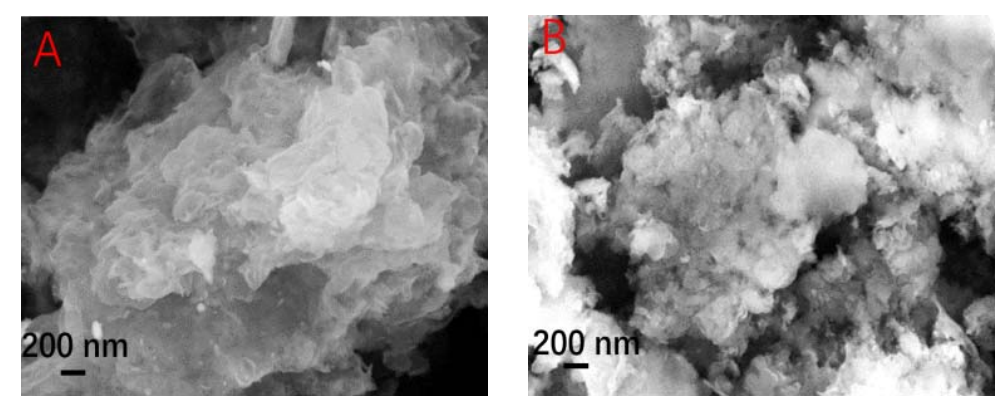

Figure 1. Cont. 

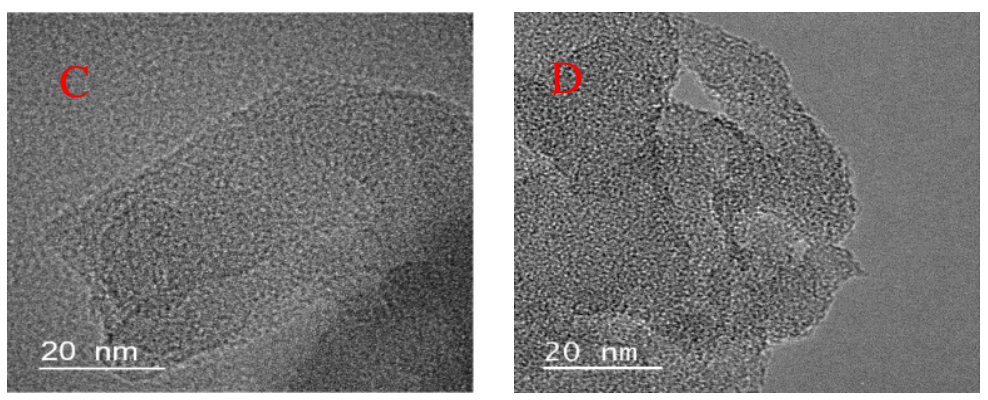

Figure 1. SEM images of (A) $\mathrm{C}_{3} \mathrm{~N}_{4} \mathrm{NS}$ and (B) $0.4 \mathrm{C}-\mathrm{C}_{3} \mathrm{~N}_{4}$ NS. High-resolution transmission electron microscope (HRTEM) images of (C) $\mathrm{C}_{3} \mathrm{~N}_{4}$ NS and (D) $0.4 \mathrm{C}-\mathrm{C}_{3} \mathrm{~N}_{4} \mathrm{NS}$.

Figure 2A shows the FTIR spectra of $\mathrm{C}_{3} \mathrm{~N}_{4}$ NS and C- $\mathrm{C}_{3} \mathrm{~N}_{4}$ NS. The peaks at $1200-1600$ and $805 \mathrm{~cm}^{-1}$ are corresponding to the characteristics of $\mathrm{C}-\mathrm{N}$ heterocycle stretches and tri-s-triazine ring modes, respectively. This phenomenon indicates that the original $\mathrm{C}_{3} \mathrm{~N}_{4}$ backbones are not damaged after the introduction of carbon doping. The peaks between $3000-3300 \mathrm{~cm}^{-1}$ are assigned to the $\mathrm{N}-\mathrm{H}$ stretching vibrations, and the peaks for the $C-C_{3} N_{4}$ NS are weaker than those for the $C_{3} N_{4}$ NS, which can be ascribed to the decrease of $N$ atoms caused by the doping of $C$ atoms at the $N$ sites $[19,20]$.

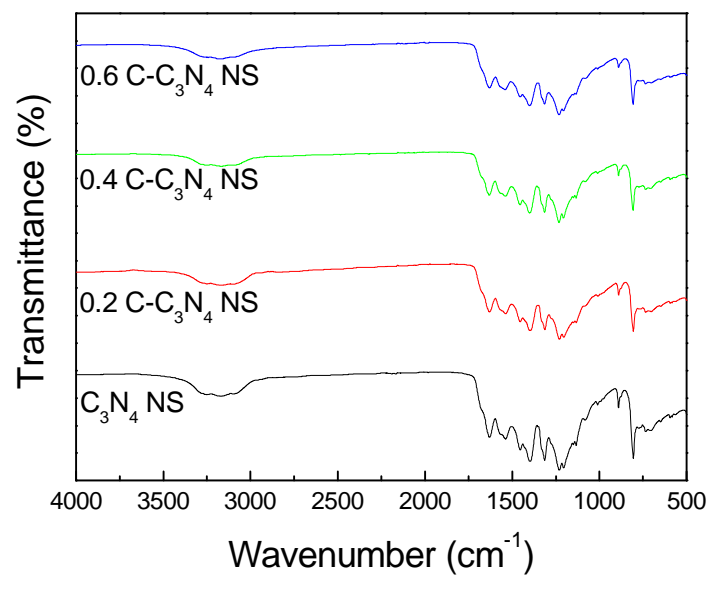

Figure 2. FTIR spectra of $\mathrm{C}_{3} \mathrm{~N}_{4}$ NS and $\mathrm{C}-\mathrm{C}_{3} \mathrm{~N}_{4}$ NS samples.

The solid-state ${ }^{13} \mathrm{C}$-magic-angle spinning (MAS)-NMR spectra of $\mathrm{C}_{3} \mathrm{~N}_{4} \mathrm{NS}$ and $0.4 \mathrm{C}-\mathrm{C}_{3} \mathrm{~N}_{4} \mathrm{NS}$ (Figure 3A) showed two strong peaks at 158.4 and $166.4 \mathrm{ppm}$, which correspond to $\mathrm{C}_{3 \mathrm{~N}}$ (1) and $\mathrm{C}_{2 \mathrm{~N}^{-} \mathrm{NHx}}(2)$ in the triazine ring units, respectively. No other peak is observed for $0.4 \mathrm{C}-\mathrm{C}_{3} \mathrm{~N}_{4} \mathrm{NS}$, indicating that the introduction of carbon does not cause the open-loop reaction of the triazine ring, and that the $C-C_{3} N_{4}$ NS remained in the original $C_{3} N_{4}$ triazine ring structure, which is similar to the above Fourier-transform infrared (FTIR) results [21]. The maintenance of these 2D conjugated backbone structures provides the prerequisite for the $\pi$-delocalized electronic systems [12].

The atomic distributions of $\mathrm{C}$ and $\mathrm{N}$ are further revealed by the electron-energy loss spectroscopy (EELS) elemental mapping. Figure 3B shows the EELS mapping of $0.4 C-C_{3} \mathrm{~N}_{4} \mathrm{NS}$, the distribution of $\mathrm{C}$ and $\mathrm{N}$ elements being shown in Figure 3C,D. $\mathrm{C}$ and $\mathrm{N}$ elements are evenly distributed throughout all the $0.4 \mathrm{C}-\mathrm{C}_{3} \mathrm{~N}_{4} \mathrm{NS}$ material, and no more carbon is observed to be coated on the edge of $0.4 \mathrm{C}-\mathrm{C}_{3} \mathrm{~N}_{4} \mathrm{NS}$, indicating that the $\mathrm{C}$ is not clustered on the $\mathrm{C}_{3} \mathrm{~N}_{4}$ surface in the form of a coated surface. Moreover, there are no carbon particles adhered to the surface of the $0.4 \mathrm{C}-\mathrm{C}_{3} \mathrm{~N}_{4} \mathrm{NS}$, as shown in the HRTEM results. Therefore, traces of introduced $C$ atoms might be embedded into the structure of the tri-s-triazine ring. The NMR results exhibit that the introduced $\mathrm{C}$ atoms do not cause the open-loop reaction of the triazine ring, and the FTIR results show that the $\mathrm{N}-\mathrm{H}$ stretching vibrations get weaker 
after the $\mathrm{C}$ doping. It can be concluded that the $\mathrm{N}$ atoms in the tri-s-triazine ring were substituted by the introduced $\mathrm{C}$ atoms.
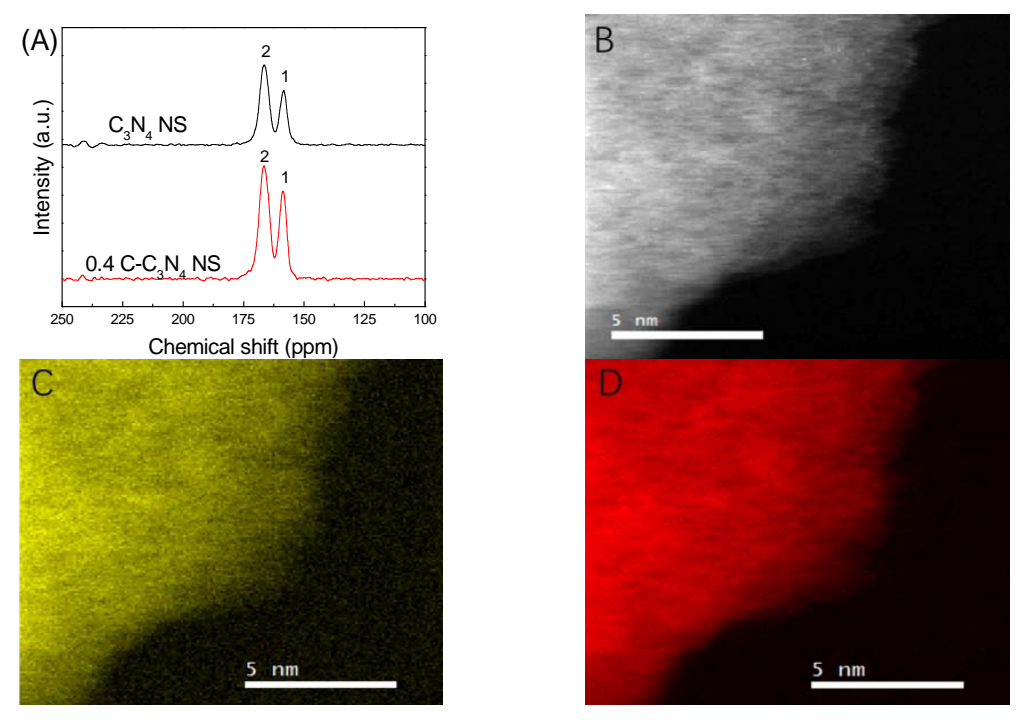

Figure 3. (A) Solid-state ${ }^{13} \mathrm{C}$-magic-angle spinning (MAS)-NMR spectra of $\mathrm{C}_{3} \mathrm{~N}_{4} \mathrm{NS}$ and $0.4 \mathrm{C}-\mathrm{C}_{3} \mathrm{~N}_{4}$ NS. (B) Electron-energy loss spectroscopy (EELS) mapping of $0.4 \mathrm{C}-\mathrm{C}_{3} \mathrm{~N}_{4} \mathrm{NS}$ for merged mapping, (C) C mapping and (D) $\mathrm{N}$ mapping.

Figure $4 \mathrm{~A}$ shows the XRD results of the $\mathrm{C}_{3} \mathrm{~N}_{4}$ NS and C- $\mathrm{C}_{3} \mathrm{~N}_{4}$ NS. All the samples exhibit two characteristic peaks at $13^{\circ}$ and $27.4^{\circ}$ corresponding to the (100) in-planar peak and the (002) interlayer-stacking peak of $\mathrm{g}-\mathrm{C}_{3} \mathrm{~N}_{4}$, respectively [2]. Enlarged XRD patterns (Figure 4B) show the gradual shift of the (002) peak to a higher angle with the introduction of carbon, indicating disturbance of the packing and undulations of the single layers. The introduction of the carbon dopant could form delocalized $\pi$-bonds that complete the $\pi$-delocalized electronic systems [22]. High-resolution $C$ 1s XPS spectra (Figure 4C) shows that the $\mathrm{C}_{3} \mathrm{~N}_{4}$ NSs were deconvoluted into two peaks at $284.9 \mathrm{eV}$ and $288.4 \mathrm{eV}$, which can be ascribed to graphitic carbon atoms and $\mathrm{sp}^{2}$-bonded carbon atoms in the heterocycle $(\mathrm{N}-\mathrm{C}=\mathrm{C})$ of aromatic $\mathrm{g}-\mathrm{C}_{3} \mathrm{~N}_{4}$, respectively [23]. For the $0.4 \mathrm{C}-\mathrm{C}_{3} \mathrm{~N}_{4} \mathrm{NS}$, the peak corresponding to $\mathrm{sp}^{2}$-bonded carbon slightly shifted to $288.3 \mathrm{eV}$, which indicated that the binding energies of carbon atoms were affected by the doped carbon. High-resolution N 1s XPS spectra (Figure $4 \mathrm{D}$ ) shows that all peaks of the $0.4 \mathrm{C}-\mathrm{C}_{3} \mathrm{~N}_{4}$ NS shifted to lower binding energy compared to those of $\mathrm{C}_{3} \mathrm{~N}_{4} \mathrm{NS}$. Therefore, the assumption that the $\mathrm{N}$ atoms in tri-s-triazine ring were substituted by $\mathrm{C}$ atoms, as shown in Figure 5, is further confirmed. The doped $\mathrm{C}$ atoms substituting $\mathrm{N}$ atoms maintained the original 2D conjugated backbone structures and reduced the number of $\mathrm{N}-\mathrm{H}$ bonds, which resulted in the abovementioned results [24].

Figure $6 \mathrm{~A}$ shows the photocatalytic hydrogen production performance of $\mathrm{C}_{3} \mathrm{~N}_{4} \mathrm{NS}$ and $\mathrm{C}-\mathrm{C}_{3} \mathrm{~N}_{4}$ NS. For $\mathrm{C}_{3} \mathrm{~N}_{4} \mathrm{NS}$, the $\mathrm{H}_{2}$ evolution rate reaches $2200.6 \pm 210.4 \mu \mathrm{mol} / \mathrm{g}$ at $4 \mathrm{~h}$, while all the $\mathrm{C}-\mathrm{C}_{3} \mathrm{~N}_{4} \mathrm{NS}$ samples exhibit higher evolution rate. Among them, $0.4 \mathrm{C}-\mathrm{C}_{3} \mathrm{~N}_{4} \mathrm{NS}$ reaches the highest $\mathrm{H}_{2}$ evolution rate of $6545.8 \pm 260.3 \mu \mathrm{mol} / \mathrm{g}$ at $4 \mathrm{~h}$, which is almost three-times higher than that of $\mathrm{C}_{3} \mathrm{~N}_{4} \mathrm{NS}$; in order to rule out the contingency of the experiment, we did three sets of parallel experiments for each set of data. Corresponding error bars are given in Figure $6 \mathrm{~A}$, and the error ranges of the $\mathrm{H}_{2}$ evolution rates are within reasonable tolerances. The corresponding volume histogram of hydrogen production is shown in Figure $6 \mathrm{~B}$, and the $0.4 \mathrm{C}-\mathrm{C}_{3} \mathrm{~N}_{4} \mathrm{NS}$ exhibits the highest hydrogen production performance as well $(1636.45 \pm 65.075 \mu \mathrm{mol} / \mathrm{g} / \mathrm{h})$. Additionally, the photocatalysis stability of the $0.4 \mathrm{C}-\mathrm{C}_{3} \mathrm{~N}_{4} \mathrm{NS}$ was tested further, as shown in Figure 6C. After four cycles, the hydrogen evolution performance of the $0.4 \mathrm{C}-\mathrm{C}_{3} \mathrm{~N}_{4} \mathrm{NS}$ sample only decreased a little, and stabilized in the third and fourth cycles, indicating the stable photocatalysis performance of $0.4 \mathrm{C}-\mathrm{C}_{3} \mathrm{~N}_{4} \mathrm{NS}$. 

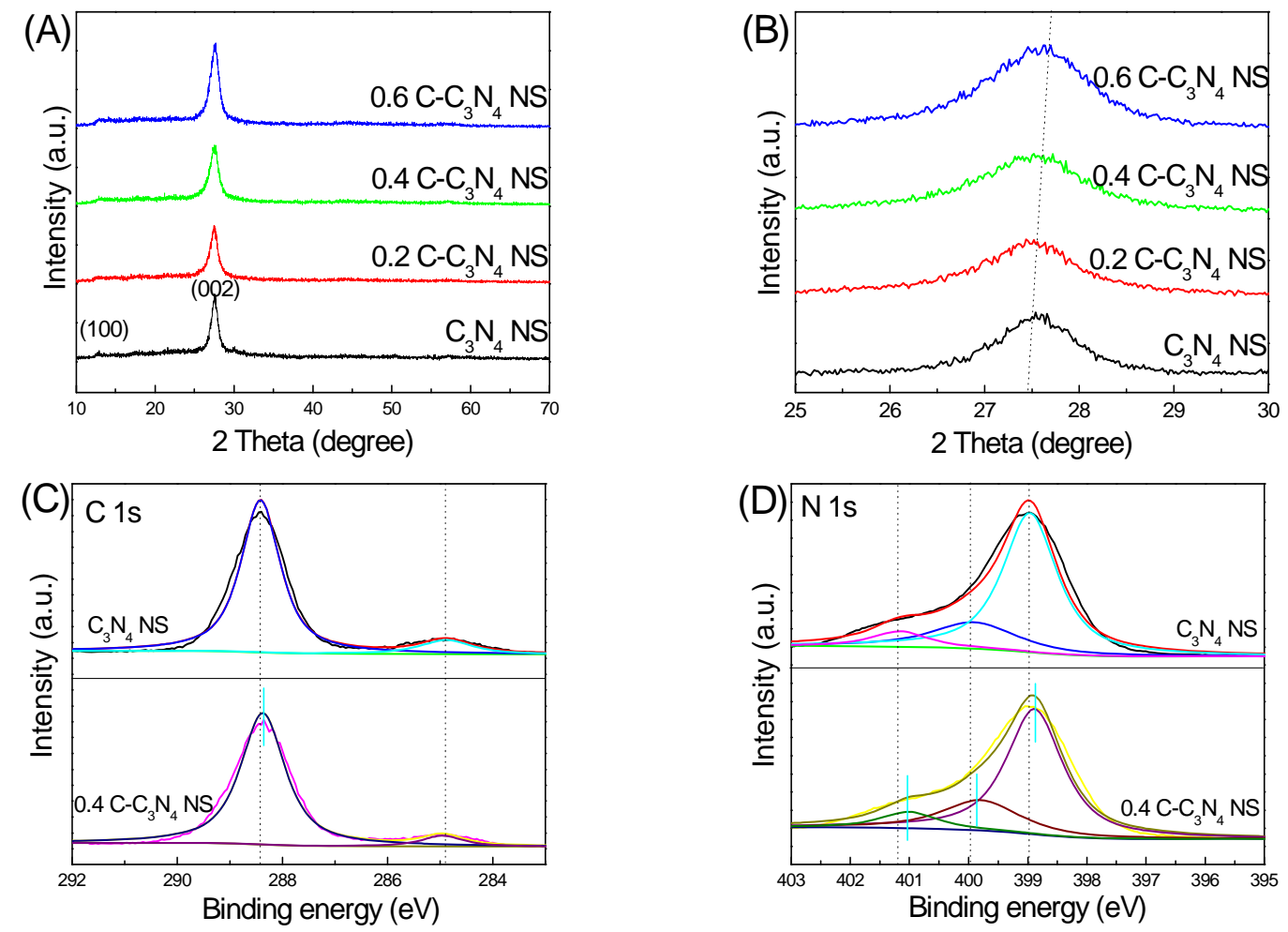

Figure 4. (A) XRD patterns and (B) enlarged XRD patterns of series samples. High-resolution XPS spectra of (C) C 1s and (D) $\mathrm{N} 1$ s of $\mathrm{C}_{3} \mathrm{~N}_{4}$ NS and $0.4 \mathrm{C}-\mathrm{C}_{3} \mathrm{~N}_{4} \mathrm{NS}$.

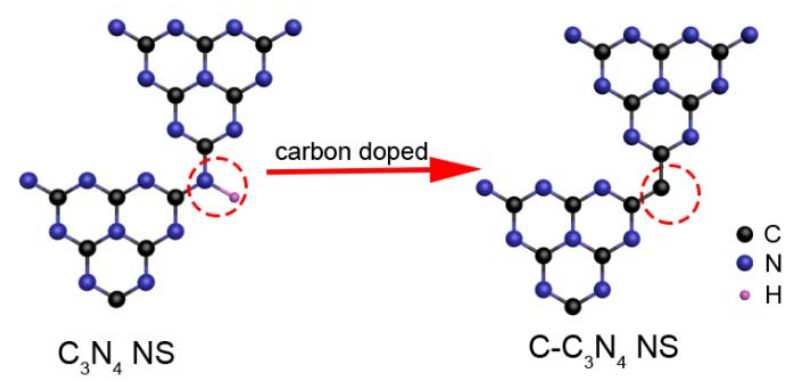

Figure 5. Atomic structure of $\mathrm{C}_{3} \mathrm{~N}_{4} \mathrm{NS}$ and $\mathrm{C}-\mathrm{C}_{3} \mathrm{~N}_{4} \mathrm{NS}$.

Figure $6 \mathrm{D}$ shows the photocatalytic rhodamine $\mathrm{B}(\mathrm{RhB})$ degradation results of the series of samples under visible-light illumination. Three sets of parallel experiments were presented to rule out the contingency of the experiment. All data errors are within reasonable tolerances, which might result from the difference in degree of centrifugation. As shown in Figure 6D, after visible-light illumination, for the $\mathrm{C}_{3} \mathrm{~N}_{4}$ NS photocatalyst, only $50 \%$ RhB could be degraded in $60 \mathrm{~min}$. However, all C-C $\mathrm{C}_{3} \mathrm{~N}_{4} \mathrm{NS}$ samples exhibited higher photocatalytic degradation rates. Among them, the $0.4 \mathrm{C}-\mathrm{C}_{3} \mathrm{~N}_{4} \mathrm{NS}$ showed the highest degradation performance, which reached approximately $95 \%$ RhB degradation in only $40 \mathrm{~min}$. 

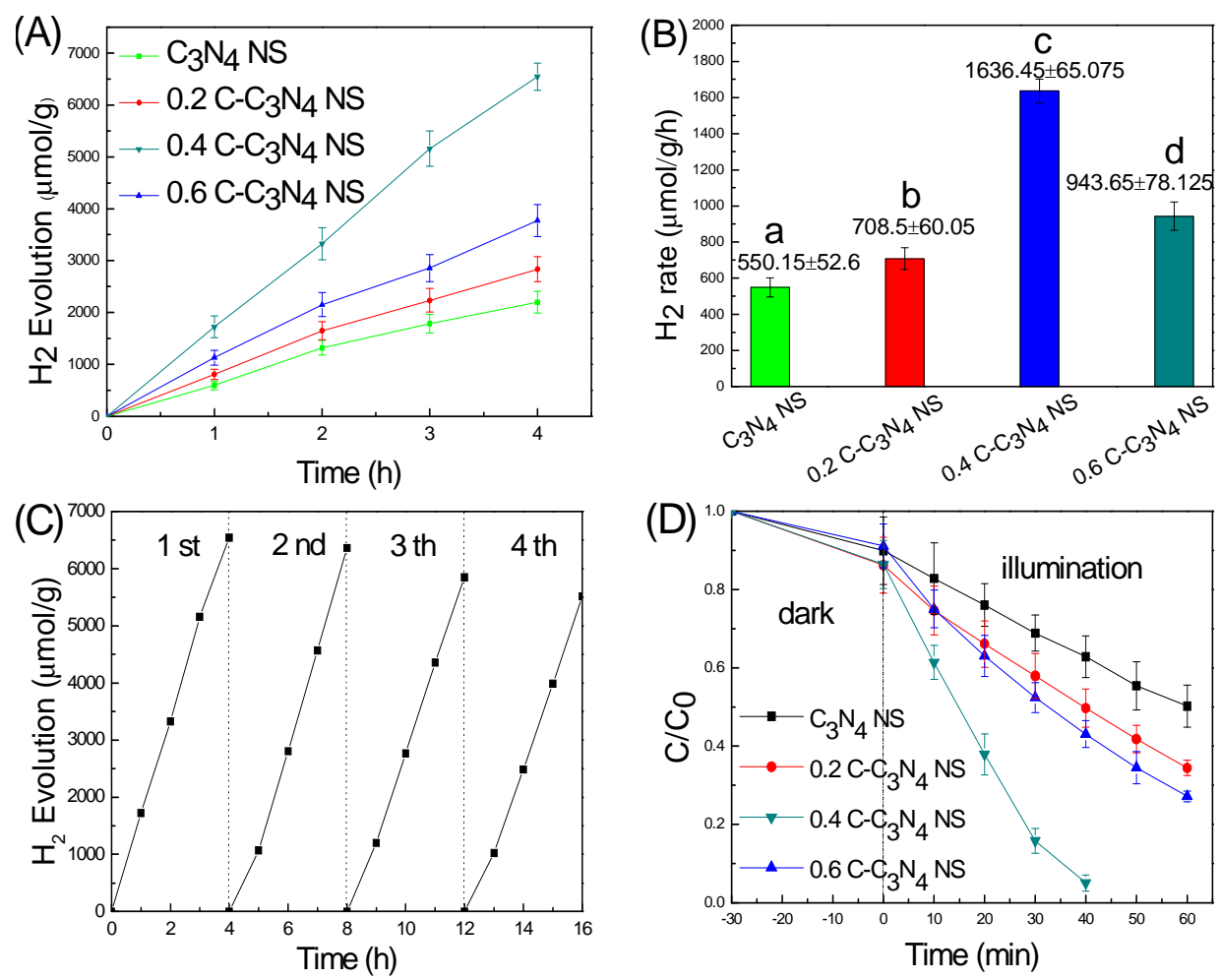

Figure 6. (A) Photocatalysis hydrogen evolution and (B) volume histogram of series of samples. (C) Photocatalysis hydrogen evolution stability test of 0.4 C $-\mathrm{C}_{3} \mathrm{~N}_{4}$ NS. (D) Photocatalysis rhodamine B (RhB) degradation performances of series of samples.

Figure 7A shows the photoinduced current with time $\mathrm{i}-\mathrm{t}$ curve of the as-prepared photoelectrodes. As shown in Figure 7A, the photoinduced currents of all C- $\mathrm{C}_{3} \mathrm{~N}_{4}$ NS photoelectrodes are much higher than those of $\mathrm{C}_{3} \mathrm{~N}_{4}$ NS. Among all C- $\mathrm{C}_{3} \mathrm{~N}_{4}$ NS samples, $0.4 \mathrm{C}-\mathrm{C}_{3} \mathrm{~N}_{4} \mathrm{NS}$ exhibits the highest photocurrent of $1.2 \mu \mathrm{A} / \mathrm{cm}^{2}$. The electrochemical impedance spectroscopy (EIS) measurement result is shown in Figure 7B; the resistance arc radius of the $0.4 \mathrm{C}-\mathrm{C}_{3} \mathrm{~N}_{4} \mathrm{NS}$ was smaller than that of the $\mathrm{C}_{3} \mathrm{~N}_{4}$ NS, suggesting that the introduction of $C$ could facilitate the charge transport of $C_{3} N_{4}$ NS [25].
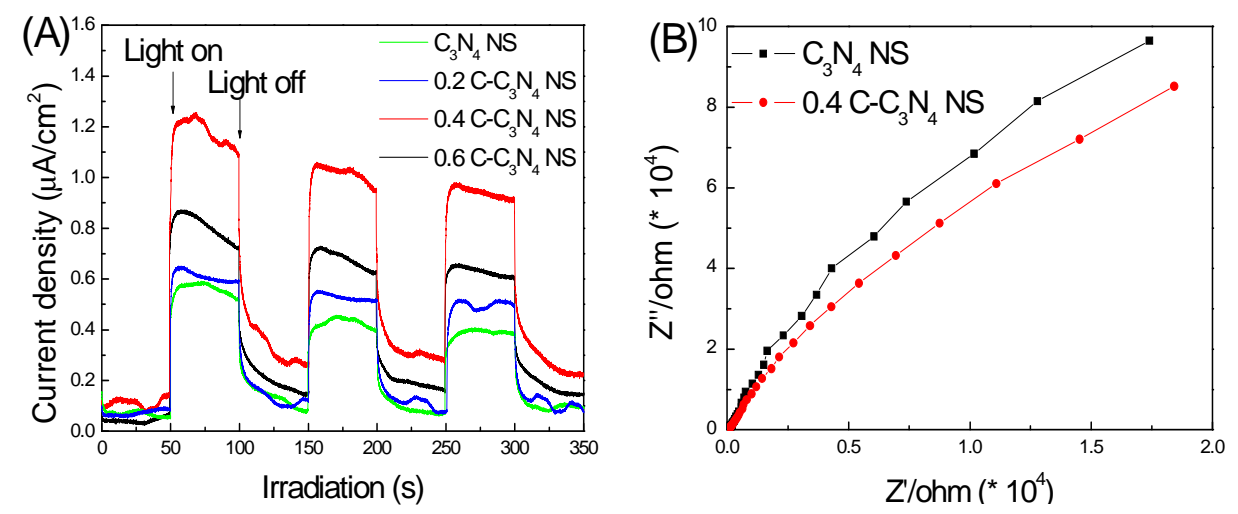

Figure 7. Cont. 

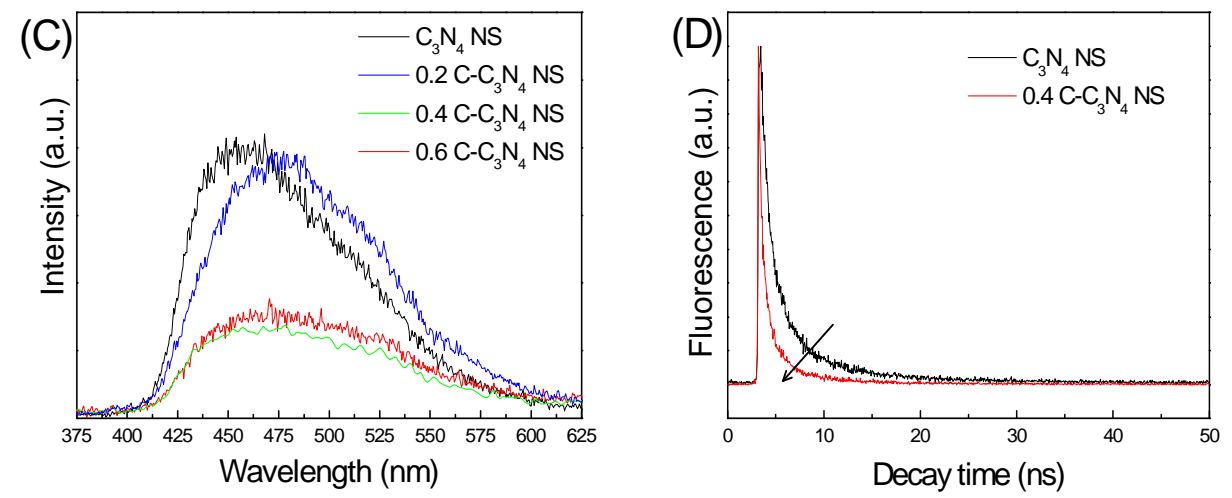

Figure 7. (A) Photoinduced current-time curves and (B) Electrochemical impedance spectroscopy (EIS) results of $\mathrm{C}_{3} \mathrm{~N}_{4}$ NS and $0.4 \mathrm{C}-\mathrm{C}_{3} \mathrm{~N}_{4}$ NS electrodes. (C) Photoluminescence spectra of series of samples. (D) Time-resolved fluorescence spectra of $\mathrm{C}_{3} \mathrm{~N}_{4} \mathrm{NS}$ and $0.4 \mathrm{C}-\mathrm{C}_{3} \mathrm{~N}_{4} \mathrm{NS}$.

In order to detect the recombination rate of photocarriers in the samples, Photoluminescence (PL) spectra were tested. As shown in Figure $7 \mathrm{C}$, all C- $\mathrm{C}_{3} \mathrm{~N}_{4}$ NS samples show decreased PL emission intensity in comparison with $\mathrm{C}_{3} \mathrm{~N}_{4} \mathrm{NS}$ ones, indicating that the recombination rate of charge carriers is suppressed by the carbon doping. Photocurrent and PL results show that the introduction of carbon improves the separation of photocarriers and inhibits the recombination rate, which promotes the photocatalytic performance [26]. Time-resolved PL spectra also support the above assumption. It is clear that the fluorescence lifetime of $0.4 \mathrm{C}-\mathrm{C}_{3} \mathrm{~N}_{4} \mathrm{NS}$ samples is shorter than that of $\mathrm{C}_{3} \mathrm{~N}_{4}$ NS (Figure 7D), and the decreased lifetime manifests more efficient separation of electrons and holes. Therefore, the doped carbon can accelerate the separation and transfer of the photogenerated carriers [27].

Diffuse reflectance spectra of the series of samples are shown in Figure 8A. It is clear that the C- $\mathrm{C}_{3} \mathrm{~N}_{4}$ samples show a progressive redshift with increasing $\mathrm{C}$ content, confirming that the bandgap can be narrowed by introducing $\mathrm{C}$. The estimated bandgaps (Figure $8 \mathrm{~B}$ ) of the series of samples are $2.04 \mathrm{eV}, 2.18 \mathrm{eV}, 2.36 \mathrm{eV}$ and $2.44 \mathrm{eV}$, corresponding to the $0.6 \mathrm{C}-\mathrm{C}_{3} \mathrm{~N}_{4} \mathrm{NS}, 0.4 \mathrm{C}-\mathrm{C}_{3} \mathrm{~N}_{4} \mathrm{NS}, 0.2 \mathrm{C}-\mathrm{C}_{3} \mathrm{~N}_{4}$ $\mathrm{NS}$ and $\mathrm{C}_{3} \mathrm{~N}_{4} \mathrm{NS}$, respectively. To further investigate the influence of $\mathrm{C}$ on the band position of the $\mathrm{C}_{3} \mathrm{~N}_{4} \mathrm{NS}$, Valence band X-ray photoelectron spectroscopy (VB-XPS) was tested for the $\mathrm{C}_{3} \mathrm{~N}_{4} \mathrm{NS}$ and $0.4 \mathrm{C}-\mathrm{C}_{3} \mathrm{~N}_{4}$ NS. As shown in Figure $8 \mathrm{C}$, the VB maximum was similar for both the $\mathrm{C}_{3} \mathrm{~N}_{4} \mathrm{NS}$ and 0.4 C- $\mathrm{C}_{3} \mathrm{~N}_{4} \mathrm{NS}$ located at $2.07 \mathrm{eV}$, which was estimated to be $1.51 \mathrm{~V}$ versus normal hydrogen electrode at $\mathrm{pH}=7$ through formula: $E_{\mathrm{NHE}} / \mathrm{V}=\phi+2.07 \mathrm{eV}-4.44(\phi=3.88 \mathrm{eV}$ : the electron work function of the analyzer) [28,29].
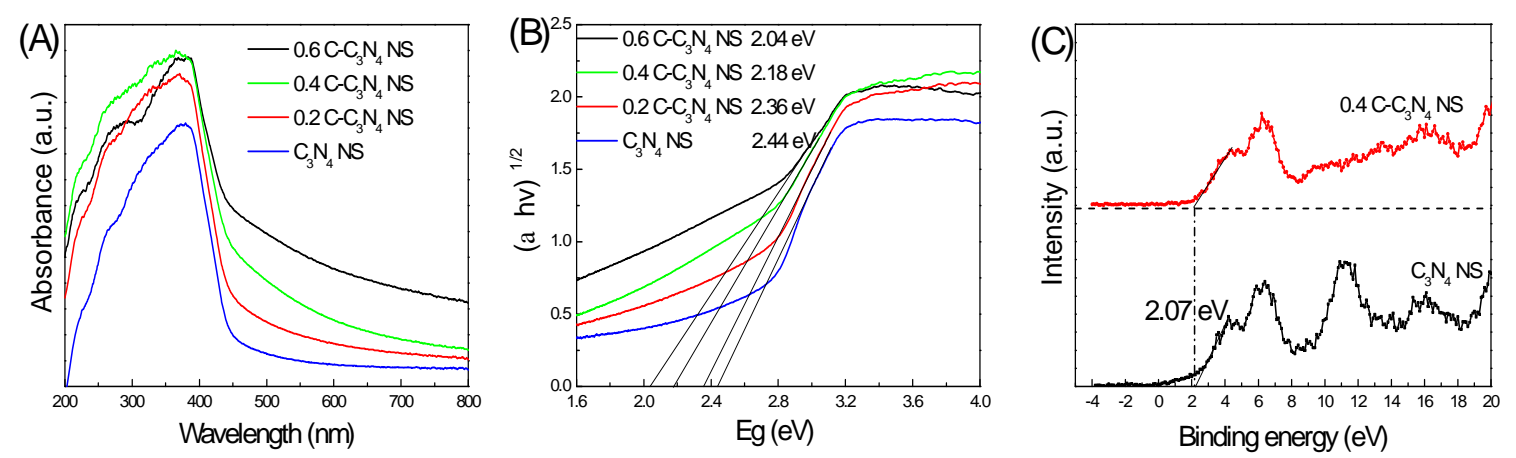

Figure 8. (A) UV-Vis diffuse reflection and (B) the estimated band gaps of series of samples. (C) VB-XPS spectra for $\mathrm{C}_{3} \mathrm{~N}_{4} \mathrm{NS}$ and $0.4 \mathrm{C}-\mathrm{C}_{3} \mathrm{~N}_{4}$ NS samples.

According to the above analysis, the VB maximum potential of $\mathrm{C}_{3} \mathrm{~N}_{4} \mathrm{NS}$ and $0.4 \mathrm{C}-\mathrm{C}_{3} \mathrm{~N}_{4} \mathrm{NS}$ samples were both located at $1.51 \mathrm{~V}$ (vs. Normal Hydrogen Electrode NHE), indicating that the valence 
band positions of the samples were unaffected by the introduction of $C$ into $g-C_{3} \mathrm{~N}_{4}$, and the estimated band gaps of the $\mathrm{C}_{3} \mathrm{~N}_{4} \mathrm{NS}$ and $0.4 \mathrm{C}-\mathrm{C}_{3} \mathrm{~N}_{4} \mathrm{NS}$ were $2.44 \mathrm{eV}$ and $2.18 \mathrm{eV}$ (Figure $8 \mathrm{~B}$ ), respectively. According to $E_{\mathrm{g}}=E_{\mathrm{v}}-E_{\mathrm{c}}$, the calculated conduction band minimum potentials of $\mathrm{C}_{3} \mathrm{~N}_{4} \mathrm{NS}$ and 0.4 $\mathrm{C}-\mathrm{C}_{3} \mathrm{~N}_{4} \mathrm{NS}$ were $-0.93 \mathrm{~V}$ and $-0.67 \mathrm{~V}$ (vs. NHE), respectively. The positive shift of the conduction band for the $0.4 \mathrm{C}-\mathrm{C}_{3} \mathrm{~N}_{4} \mathrm{NS}$ was caused by the formation of doped energy level which comes from the C. The estimated band structure schematic is exhibited in Figure 9.

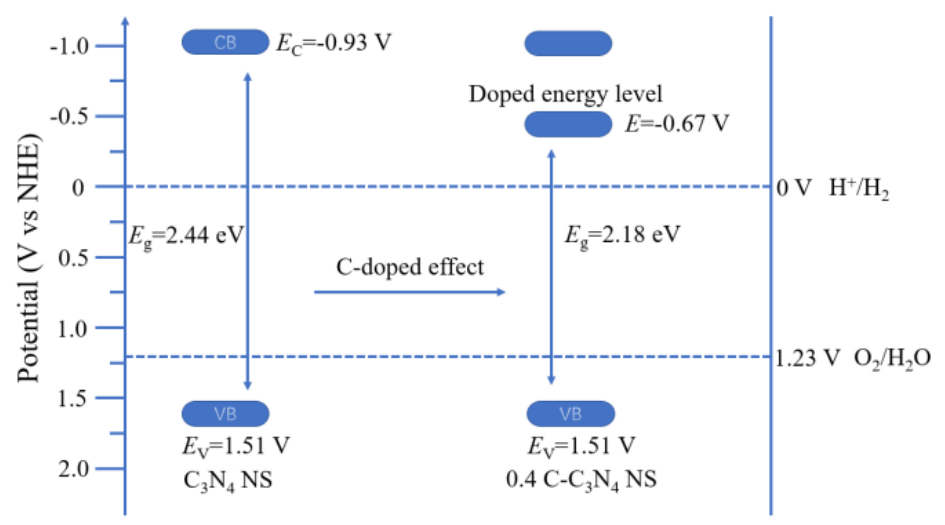

Figure 9. Band structure of the $\mathrm{C}_{3} \mathrm{~N}_{4} \mathrm{NS}$ and $0.4 \mathrm{C}-\mathrm{C}_{3} \mathrm{~N}_{4} \mathrm{NS}$.

Figure 10 shows the mechanism for the improvement of the photocatalysis performance under visible light. The substitution of $\mathrm{C}$ atoms for $\mathrm{N}$ atoms in the tri-s-triazine ring maintained the $2 \mathrm{D}$ conjugated system of $\mathrm{g}-\mathrm{C}_{3} \mathrm{~N}_{4}$, while the introduction of doped carbon atoms accelerates the charge mobility, thus enhancing the photocatalytic performance.

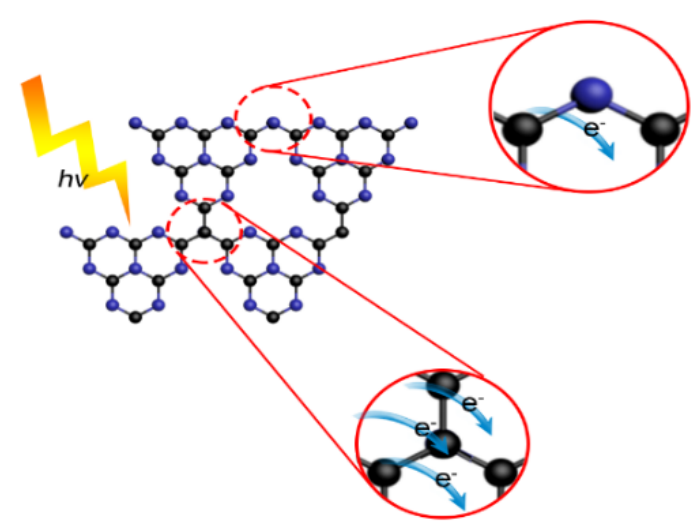

Figure 10. Mechanism of the photocatalysis performance improvement under visible light.

\section{Experimental Section}

\subsection{Fabrication of $g-C_{3} N_{4}$}

The bulk g- $\mathrm{C}_{3} \mathrm{~N}_{4}$ was prepared through traditional thermal condensation [4]. $10 \mathrm{~g}$ dicyandiamide (Aladdin Co., Shanghai, China) was annealed at $550{ }^{\circ} \mathrm{C}$ with a ramping rate of $10{ }^{\circ} \mathrm{C} \cdot \mathrm{min}^{-1}$ in air in a muffle furnace for $3 \mathrm{~h}$ to obtain a yellow powder.

\subsection{Fabrication of C-Modified $g-C_{3} N_{4}$}

In a typical synthesis, $1 \mathrm{~g} \mathrm{~g}-\mathrm{C}_{3} \mathrm{~N}_{4}$ was dissolved in $50 \mathrm{~mL}$ deionized water and sonicated for a few minutes. Then, a different mass of glucose $(0.2 \mathrm{~g}, 0.4 \mathrm{~g}, 0.6 \mathrm{~g}$, Aladdin Co., Shanghai, China) was added with stirring and then kept stirring for $1 \mathrm{~h}$. The product was centrifuged at $8000 \mathrm{r} / \mathrm{min}$ for $2 \mathrm{~min}$ 
and rinsed with water and ethanol for three times, and then dried at $60^{\circ} \mathrm{C}$ for $12 \mathrm{~h}$. The mixture was annealed at $550{ }^{\circ} \mathrm{C}$ with a ramping rate of $10^{\circ} \mathrm{C} / \mathrm{min}$ in air in a muffle furnace for $3 \mathrm{~h}$, the samples being denoted as $0.2 C-C_{3} \mathrm{~N}_{4} \mathrm{NS}, 0.4 \mathrm{C}-\mathrm{C}_{3} \mathrm{~N}_{4} \mathrm{NS}, 0.6 \mathrm{C}-\mathrm{C}_{3} \mathrm{~N}_{4} \mathrm{NS}$, respectively. For comparison, $\mathrm{C}_{3} \mathrm{~N}_{4}$ NS was prepared at the same condition in the absence of glucose. The procedure is shown as Figure 11.

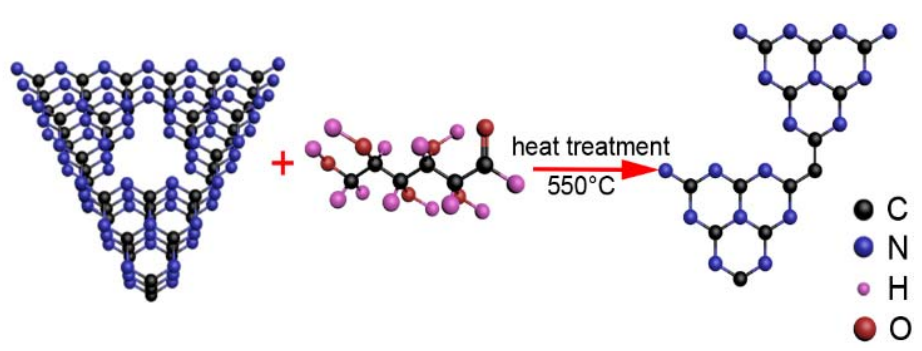

Figure 11. Schematic illustration for the formation of $C-\mathrm{C}_{3} \mathrm{~N}_{4}$ NS.

\subsection{Characterization}

The crystalline structures of the samples were identified through X-ray diffraction (XRD, D/MAX-2500/PC, Rigaku Co., Tokyo, Japan). The micro-morphologies of the samples were observed using a field-emission scanning electron microscope (SEM, JSM-6700F, JEOL, Tokyo, Japan) and a high-resolution transmission electron microscope (HRTEM, Tecnai G2 F20, FEI, Hillsboro, OR, USA). The atomic distributions of samples were further revealed by the electron energy loss spectroscopy (EELS, GIF Quantum 965, Gatan, Pleasanton, CA, USA) elemental mapping. The C atomic chemical states of samples were conducted by solid-state ${ }^{13} \mathrm{C}$ magic-angle spinning (MAS) NMR (DiscoveryMR750 3.0T, General Electric Company, Boston, MA, USA) measurements at room temperature. The elementary compositions and bonding information of the samples were analyzed by using X-ray photoelectron spectroscopy (XPS, Axis Ultra, Kratos Analytical Ltd., Manchester, England, UK). The optical absorptions of the solid-state samples were tested by a UV-visible diffuse reflectance spectrophotometer (UV-vis DRS, U-41000, HITACHI, Tokyo, Japan). The photoluminescence and fluorescence decay times of the as-prepared materials were characterized using a fluorescence spectrometer (PL, Fluoro Max-4, HORIBA Jobin Yvon, Paris, France) with excitation wavelength at $350 \mathrm{~nm}$. The molecular structures of the samples were identified through Fourier-transform infrared (FT-IR) spectra which used a Nicolet IS10 infrared spectrophotometer (Thermo Fisher Scientific, Waltham, MA, USA) in the transmission mode using a KBr pellet method.

\subsection{Photocatalytic Reaction}

The photocatalytic activities of the samples were tested by photocatalytic hydrogen production and photocatalytic dye degradation under visible light. In photocatalytic hydrogen production test, $50 \mathrm{mg}$ catalyst powder was dispersed in $100 \mathrm{~mL}$ aqueous solution which contained $10 \mathrm{vol} \%$ triethanolamine as sacrificial electron donor and $3 \mathrm{wt} \% \mathrm{H}_{2} \mathrm{PtCl}_{6} \cdot 6 \mathrm{H}_{2} \mathrm{O}$ (Aladdin Co., Shanghai, China) as a co-catalyst [30]. Before the test, the photoreaction system was vacuumed until the pressure gage was stable. Externally illuminating $150 \mathrm{~W}$ Xe lamp (PLS-SXE300, Beijing Changtuo Co., Ltd., Beijing, China) was used as light source, and we added a $420 \mathrm{~nm}$ cut-off filter to achieve visible light, and adjusted the photo density to $250 \mathrm{~mW} / \mathrm{cm}^{2}$. The illuminated area of the photocatalytic reaction is $28.3 \mathrm{~cm}^{2}$ (light spot diameter is $6 \mathrm{~cm}$ ). The entire reaction system was kept at a constant $5{ }^{\circ} \mathrm{C}$ with condensed water. In photocatalytic dye degradation test, rhodamine B (RhB, Aladdin Co., Shanghai, China) was selected as the target degradant. The specific experimental steps are as follows: $0.05 \mathrm{~g}$ photocatalyst was dispersed in $100 \mathrm{~mL} \mathrm{RhB}$ with a concentration of $10 \mathrm{mg} \cdot \mathrm{L}^{-1}$. Before illumination, the mixture kept stirring for $30 \mathrm{~min}$ in the dark to achieve adsorption-desorption equilibrium. The light source and photo density were kept the same with the photocatalytic hydrogen production test. The entire reaction system was maintained at $25^{\circ} \mathrm{C}$ with circulating water. The light 
absorptivity of solutions were decided by the UV-visible absorption spectrophotometer (U-41000, HITACHI, Tokyo, Japan) every $10 \mathrm{~min}$ after centrifugation with the speed of $8000 \mathrm{r} / \mathrm{min}$ for $2 \mathrm{~min}$.

\subsection{Photoelectrode Preparation and Photoelectrochemical Reaction}

The photoelectrodes were prepared through electrophoretic deposition method. In total, $20 \mathrm{mg}$ photocatalyst was dispersed in $50 \mathrm{~mL}$ water containing $5 \mathrm{mg} \mathrm{I}_{2}$, the mixture was stirred for $30 \mathrm{~min}$ to completely dissolve. Then, two Fluorine-doped Tin Oxide (FTO) conductive glasses with the deposition area of $1 \mathrm{~cm} \times 1 \mathrm{~cm}$ and a distance $1 \mathrm{~cm}$ were immersed into the solution, maintaining a bias voltage of $20 \mathrm{~V}$ and a deposition time of $5 \mathrm{~min}$. The obtained photoelectrodes were annealed at $300{ }^{\circ} \mathrm{C}$ for $30 \mathrm{~min}$ to improve adhesion. The photoelectrochemical systems were measured in a three-electrode system. The as-prepared photoelectrodes, and platinum and $\mathrm{Ag} / \mathrm{AgCl}$ electrodes, were used as the working, counter and reference electrodes, respectively. $0.1 \mathrm{M} \mathrm{Na}_{2} \mathrm{SO}_{4}$ was used as electrolyte. All photoelectrochemical tests were measured using a CHI-660D (Chenhua Instrument Co., Shanghai, China) electrochemical workstation. The photoinduced current density-time (i-t) curves were measured at $1 \mathrm{~V}$ (vs. $\mathrm{Ag} / \mathrm{AgCl}$ ) bias under visible light with the photo density at $100 \mathrm{~mW} / \mathrm{cm}^{2}$. The electrochemical impedance spectroscopy (EIS) was measured at $0 \mathrm{~V}$ (vs. $\mathrm{Ag} / \mathrm{AgCl}$ ) bias with the frequency range from $10^{5}-10^{-1} \mathrm{~Hz}$.

\section{Conclusions}

In summary, we developed $\mathrm{C}$ self-doped g- $\mathrm{C}_{3} \mathrm{~N}_{4}$ by a simple co-condensation method, and carbon atoms were successfully introduced into the tri-s-triazine structure of $\mathrm{g}-\mathrm{C}_{3} \mathrm{~N}_{4}$. The secondary heat treatment exfoliated the bulk $\mathrm{g}-\mathrm{C}_{3} \mathrm{~N}_{4}$ to nanosheets, which endows materials with higher specific surface area. Compared with pure g- $\mathrm{C}_{3} \mathrm{~N}_{4}$, the modified $\mathrm{C}$ substitutes $\mathrm{N}$ atoms in the triazine ring, which broadens the range of light absorption, accelerates the transfer rate of charge carriers as well as increases the photocatalysis performance. Among all the $\mathrm{C}-\mathrm{C}_{3} \mathrm{~N}_{4} \mathrm{NS}$ samples, the optimal $0.4 \mathrm{C}-\mathrm{C}_{3} \mathrm{~N}_{4}$ NS unfolds the superior photocatalytic hydrogen rate of $1636.45 \mu \mathrm{mol} / \mathrm{g} / \mathrm{h}$, which is almost three-times higher than that of pure $\mathrm{C}_{3} \mathrm{~N}_{4} \mathrm{NS}$. Simultaneously, the $0.4 \mathrm{C}-\mathrm{C}_{3} \mathrm{~N}_{4} \mathrm{NS}$ shows a better photocatalytic $\mathrm{RhB}$ degradation rate than that of the $\mathrm{C}_{3} \mathrm{~N}_{4} \mathrm{NS}$ under visible light illumination, the former of which could achieve approximately $95 \%$ degradation in $40 \mathrm{~min}$. The photoelectrochemical test results verify that the introduction of $\mathrm{C}$ accelerates the transfer rate and inhibits the combination of photo-induced carriers, while also enhancing the photocatalytic performance. This work highlights how carbon modification incorporated into g- $\mathrm{C}_{3} \mathrm{~N}_{4}$ has improved the photocatalytic performance without destroying the $2 \mathrm{D}$ conjugated backbone structures.

Author Contributions: Conceptualization, D.Y., W.L.; Methodology, H.W.; Experiment and Analysis, Z.C., G.H. Funding: This research received no external funding.

Acknowledgments: This work was financially supported by the Research Fund of State Key Laboratory for Marine Corrosion and Protection of Luoyang Ship Material Research Institute (LSMRI) under the contract No. KF160413.

Conflicts of Interest: The authors declare no conflict of interest.

\section{References}

1. Maeda, K. Photocatalytic water splitting using semiconductor particles: History and recent developments. J. Photochem. Photobiol. C 2011, 12, 237-268. [CrossRef]

2. Wang, X.; Maeda, K.; Thomas, A.; Takanabe, K.; Xin, G.; Carlsson, J.M.; Domen, K.; Antonietti, M. A metal-free polymeric photocatalyst for hydrogen production from water under visible light. Nat. Mater. 2009, 8, 76-80. [CrossRef] [PubMed]

3. Ong, W.; Tan, L.; Ng, Y.; Yong, S.; Chai, S. Graphitic carbon nitride (g- $\left.\mathrm{C}_{3} \mathrm{~N}_{4}\right)$-based photocatalysts for artificial photosynthesis and environmental remediation: Are we a step closer to achieving sustainability? Chem. Rev. 2016, 116, 7159-7329. [CrossRef] [PubMed] 
4. $\quad \mathrm{Bu}, \mathrm{Y}$; Chen, Z.; Xie, T.; Li, W.; Ao, J. Fabrication of $\mathrm{C}_{3} \mathrm{~N}_{4}$ ultrathin flakes by mechanical grind method with enhanced photocatalysis and photoelectrochemical performance. RSC Adv. 2016, 6, 47813-47819. [CrossRef]

5. Han, Q.; Wang, B.; Zhao, Y.; Hu, C.; Qu, L. A Graphitic- $\mathrm{C}_{3} \mathrm{~N}_{4}$ "Seaweed" Architecture for Enhanced Hydrogen Evolution. Angew. Chem. Int. Ed. 2015, 54, 11433-11437. [CrossRef] [PubMed]

6. Fu, J.; Chang, B.; Tian, Y.; Xi, F.; Dong, X. Novel $\mathrm{C}_{3} \mathrm{~N}_{4}$-CdS composite photocatalysts with organic-inorganic heterojunctions: In situ synthesis, exceptional activity, high stability and photocatalytic mechanism. J. Mater. Chem. A 2013, 1, 3083-3090. [CrossRef]

7. Zhang, J.; Wang, Y.; Jin, J.; Zhang, J.; Lin, Z.; Huang, F.; Yu, J. Efficient visible-light photocatalytic hydrogen evolution and enhanced photostability of core/shell CdS/g- $\mathrm{C}_{3} \mathrm{~N}_{4}$ nanowires. ACS Appl. Mater. Interfaces 2013, 5, 10317-10324. [CrossRef] [PubMed]

8. Li, Q.; Zhang, N.; Yang, Y.; Wang, G.; Ng, D.H. High efficiency photocatalysis for pollutant degradation with $\mathrm{MoS}_{2} / \mathrm{C}_{3} \mathrm{~N}_{4}$ heterostructures. Langmuir 2014, 30, 8965-8972. [CrossRef] [PubMed]

9. Wang, Y.; Shi, R.; Lin, J.; Zhu, Y. Enhancement of photocurrent and photocatalytic activity of ZnO hybridized with graphite-like $\mathrm{C}_{3} \mathrm{~N}_{4}$. Energy Environ. Sci. 2011, 4, 2922-2929. [CrossRef]

10. Yan, H.; Yang, $\mathrm{H}$. $\mathrm{TiO}_{2}-\mathrm{g}-\mathrm{C}_{3} \mathrm{~N}_{4}$ composite materials for photocatalytic $\mathrm{H}_{2}$ evolution under visible light irradiation. J. Alloys Compd. 2011, 509, L26-L29. [CrossRef]

11. Lan, Z.; Zhang, G.; Wang, X. A facile synthesis of Br-modified g- $\mathrm{C}_{3} \mathrm{~N}_{4}$ semiconductors for photoredox water splitting. Appl. Catal. B Environ. 2016, 192, 116-125. [CrossRef]

12. Zhang, G.; Zhang, M.; Ye, X.; Qiu, X.; Lin, S.; Wang, X. Iodine modified carbon nitride semiconductors as visible light photocatalysts for hydrogen evolution. Adv. Mater. 2014, 26, 805-809. [CrossRef] [PubMed]

13. Tian, H.; Zhang, X.; Bu, Y. Sulfur-and Carbon-Codoped Carbon Nitride for Photocatalytic Hydrogen Evolution Performance Improvement. ACS Sustain. Chem. Eng. 2018, 6, 7346-7354. [CrossRef]

14. Guo, S.; Tang, Y.; Xie, Y.; Tian, C.; Feng, Q.; Zhou, W.; Jiang, B. P-doped tubular g- $\mathrm{C}_{3} \mathrm{~N}_{4}$ with surface carbon defects: Universal synthesis and enhanced visible-light photocatalytic hydrogen production. Appl. Catal. B Environ. 2017, 218, 664-671. [CrossRef]

15. Yan, S.; Li, Z.; Zou, Z. Photodegradation of rhodamine B and methyl orange over boron-doped g- $\mathrm{C}_{3} \mathrm{~N}_{4}$ under visible light irradiation. Langmuir 2010, 26, 3894-3901. [CrossRef] [PubMed]

16. Wang, Y.; Di, Y.; Antonietti, M.; Li, H.; Chen, X.; Wang, X. Excellent visible-light photocatalysis of fluorinated polymeric carbon nitride solids. Chem. Mater. 2010, 22, 5119-5121. [CrossRef]

17. Zhang, H.; Zhao, L.; Geng, F.; Guo, L.; Wan, B.; Yang, Y. Carbon dots decorated graphitic carbon nitride as an efficient metal-free photocatalyst for phenol degradation. Appl. Catal. B Environ. 2016, 180, 656-662. [CrossRef]

18. Niu, P.; Zhang, L.; Liu, G.; Cheng, H. Graphene-like carbon nitride nanosheets for improved photocatalytic activities. Adv. Funct. Mater. 2012, 22, 4763-4770. [CrossRef]

19. Liu, C.; Zhang, Y.; Dong, F.; Reshak, A.H.; Ye, L.; Pinna, N.; Zeng, C.; Zhang, T.; Huang, H. Chlorine intercalation in graphitic carbon nitride for efficient photocatalysis. Appl. Catal. B Environ. 2017, 203, 465-474. [CrossRef]

20. Liu, G.; Zhao, G.; Zhou, W.; Liu, Y.; Pang, H.; Zhang, H.; Hao, D.; Meng, X.; Li, P.; Kako, T.; Ye, J. In situ bond modulation of graphitic carbon nitride to construct $\mathrm{p}-\mathrm{n}$ homojunctions for enhanced photocatalytic hydrogen production. Adv. Funct. Mater. 2016, 26, 6822-6829. [CrossRef]

21. Tian, N.; Zhang, Y.; Li, X.; Xiao, K.; Du, X.; Dong, F.; Waterhouse, G.I.N.; Zhang, T.; Huang, H. Precursor-reforming protocol to $3 \mathrm{D}$ mesoporous $\mathrm{g}-\mathrm{C}_{3} \mathrm{~N}_{4}$ established by ultrathin self-doped nanosheets for superior hydrogen evolution. Nano Energy 2017, 38, 72-81. [CrossRef]

22. Ding, Y.; Tang, Y.; Yang, L.; Zeng, Y.; Yuan, J.; Liu, T.; Zhang, S.; Liu, C.; Luo, S. Porous nitrogen-rich carbon materials from carbon self-repairing g- $\mathrm{C}_{3} \mathrm{~N}_{4}$ assembled with graphene for high-performance supercapacitor. J. Mater. Chem. A 2016, 4, 14307-14315. [CrossRef]

23. Cao, S.; Low, J.; Yu, J.; Jaroniec, M. Polymeric photocatalysts based on graphitic carbon nitride. Adv. Mater. 2015, 27, 2150-2176. [CrossRef] [PubMed]

24. Li, H.; Li, F.; Wang, Z.; Jiao, Y.; Liu, Y.; Wang, P.; Zhang, X.; Qin, X.; Dai, Y.; Huang, B. Fabrication of carbon bridged $\mathrm{g}-\mathrm{C}_{3} \mathrm{~N}_{4}$ through supramolecular self-assembly for enhanced photocatalytic hydrogen evolution. Appl. Catal. B Environ. 2018, 229, 114-120. [CrossRef] 
25. Wang, R.; Xie, T.; Zhang, T.; Pu, T.; Bu, Y.; Ao, J.P. Fabrication of FTO-BiVO $4-\mathrm{W}-\mathrm{WO}_{3}$ photoanode for photoelectrochemical performance improving: Based on the Z-scheme electron transfer mechanism. J. Mater. Chem. A 2018, 6, 12956-12961. [CrossRef]

26. Jing, L.; Qu, Y.; Wang, B.; Li, S.; Jiang, B.; Yang, L.; Fu, W.; Fu, H.; Sun, J. Review of photoluminescence performance of nano-sized semiconductor materials and its relationships with photocatalytic activity. Sol. Energy Mater. Sol. Cells 2006, 90, 1773-1787.

27. Li, Y.; Xu, H.; Ouyang, S.; Lu, D.; Wang, X.; Wang, D.; Ye, J. In situ surface alkalinized g- $\mathrm{C}_{3} \mathrm{~N}_{4}$ toward enhancement of photocatalytic $\mathrm{H}_{2}$ evolution under visible-light irradiation. J. Mater. Chem. A 2016, 4, 2943-2950. [CrossRef]

28. Yu, H.; Shi, R.; Zhao, Y.; Bian, T.; Zhao, Y.; Zhou, C.; Waterhouse, G.I.N.; Wu, L.; Tung, C.; Zhang, T. Alkali-Assisted Synthesis of Nitrogen Deficient Graphitic Carbon Nitride with Tunable Band Structures for Efficient Visible-Light-Driven Hydrogen Evolution. Adv. Mater. 2017, 29, 1605148. [CrossRef] [PubMed]

29. Trasatti, S. The absolute electrode potential: An explanatory note (Recommendations 1986). Pure Appl. Chem. 1986, 58, 955-966. [CrossRef]

30. Iqbal, W.; Qiu, B.; Zhu, Q.; Xing, M.; Zhang, J. Self-modified breaking hydrogen bonds to highly crystalline graphitic carbon nitrides nanosheets for drastically enhanced hydrogen production. Appl. Catal. B Environ. 2018, 232, 306-313. [CrossRef]

(C) 2018 by the authors. Licensee MDPI, Basel, Switzerland. This article is an open access article distributed under the terms and conditions of the Creative Commons Attribution (CC BY) license (http://creativecommons.org/licenses/by/4.0/). 